\title{
Hérnia de Bochdalek: Relato de Caso
}

\author{
Bochdalek's Hernia: Case Report \\ Hernia de Bochdalek: Relato de caso
}

Fábio Ribeiro Azevedo da Silva ${ }^{1 *}$, Fernanda Costa Pereira ${ }^{1}$, Phillipe Bugner ${ }^{1}$, Isabela de Oliveira Kaluf $^{2}$, Isabela Simieli², Bruna Lima Daher².

\section{RESUMO}

Objetivo: Relatar um caso de hérnia de Bochdalek em adulto e discutir sua prevalência e manifestações clinicas. Relato de caso: Paciente masculino, 37 anos, deu entrada na emergência queixando-se de dor abdominal difusa e continua há cinco dias, associada a dispneia, náuseas, vômitos fecaloides, inapetência, parada de eliminação de flatos e fezes. O quadro era refratário ao uso de antieméticos e antiácidos. Nega história de traumas. Ao exame, abdômen distendido, ruídos hidroaéreos aumentados e doloroso à palpação. Realizada tomografia, com sinais sugestivos de abdômen agudo obstrutivo. Foi submetido a laparotomia exploradora de urgência e identificado saco herniário em região póstero-lateral esquerda do diafragma com estrangulamento de colón. Considerações finais: A hérnia de Bochdalek comumente manifesta-se em neonatos. Em adultos, sua ocorrência é rara, predominando à direita e em mulheres. Pode apresentar-se com sintomas gastrintestinais e respiratórios inespecíficos e quadro agudo de encarceramento ou perfuração. Há, portanto, a necessidade de raciocínio clínico para seu diagnóstico associado a técnicas de imagem.

Palavras-Chave: Hérnia diafragmática congênita, Adulto, Laparotomia.

\begin{abstract}
Objective: To report a case of Bochdalek hernia in adults and discuss their prevalence and clinical manifestations. Case report: A 37-year-old male patient was admitted to the emergency room complaining of diffuse abdominal pain and continued for five days, associated with dyspnoea, nausea, fecaloid vomiting, inappetence, flatus and stool elimination stopping. The picture was refractory to the use of anti-acidosis and antacids. Deny history of traumas. On examination, distended abdomen, increased hydroaic noise and painful palpation. Tomography was performed, with signs suggestive of acute obstructive abdomen. She underwent emergency exploratory laparotomy and identified hernia sac in the left post-lateral region of the diaphragm with colon strangulation. Final considerations: Bochdalek hernia is commonly seen in neonates. In adults, its occurrence is rare, predominating on the right and in women. It may present with non-specific gastrointestinal and respiratory symptoms and acute incarceration or perforation. There is, therefore, the need for clinical reasoning for its diagnosis associated with imaging techniques.
\end{abstract}

Key words: Hernias, diaphragmatic, congenital, Adult, Laparotomy.

RESUMEN

Objetivo: Relatar un caso de hernia de Bochdalek en adultos y discutir su prevalencia y manifestaciones clínicas. Relato de caso: El paciente masculino, de 37 años, entró en la emergencia quejándose de dolor

${ }^{1}$ Fundação Santa Casa de Misericórdia de Franca, Franca-São Paulo

2Universidade de Franca (UNIFRAN), Franca-São Paulo. *E-mail: brunadaher@gmail.com

SUBMETIDO EM: 7/2019

ACEITO EM: $8 / 2019$

PUBLICADO EM: 10/2019

REAS/EJCH | Vol.Sup.34 | e1351| DOI: https://doi.org/10.25248/reas.e1351.2019 Página 1 de 7 
abdominal difuso y continúa hace cinco días, asociada a disnea, nauseas, vómitos fecaloides, inapetencia, parada de eliminación de flatos y heces. El cuadro era refractario al uso de antiémeticos y antiácidos. Nega historia de traumas. Al examen, abdomen distendido, ruidos hidroaéricos aumentados y doloroso a la palpación. Realizada tomografía, con signos sugestivos de abdomen agudo obstructivo. Fue sometido a laparotomía exploradora de urgencia e identificado saco herniario en región postero-lateral izquierda del diafragma con estrangulación de colon. Consideraciones finales: La hernia de Bochdalek comúnmente se manifiesta en los recién nacidos. En adultos, su ocurrencia es rara, predominando a la derecha y en mujeres. Puede presentarse con síntomas gastrointestinales y respiratorios inespecíficos y cuadro agudo de encarcelamiento o perforación. Hay, por lo tanto, la necesidad de raciocinio clínico para su diagnóstico asociado a técnicas de imagen.

Palabras clave: Hernias diafragmáticas congénitas, Adulto, Laparotomía.

\section{INTRODUÇÃO}

A Hérnia de Bochdalek é assim chamada por traduzir um defeito no forame diafragmático pósterolateral, também denominado forame de Bochdalek (TAVARES FLS, et a., 2016). Foi descrita pela primeira vez em 1848 por Vincent Alexander Bochdalek (2018), e caracteriza-se pela evisceração transdiafragmática do conteúdo abdominal para o interior do tórax (BROWN GL e RICHARDSON JD, 1985).

É considerada congênita quando há falha na oclusão do canal pleuroperitoneal na sua porção posterolateral durante o período embrionário, o que ocorre entre a sexta e a oitava semana de vida intrauterina (MOREIRA MEL, et al., 2004). O que predispõe à deficiência do fechamento pode ser a presença de uma mutação genética, de um teratógeno, ou de ambos (NETTO JMS, et al., 2015).

De todas as hérnias diafragmáticas congênitas, entre 85 a 90\% são do tipo Bochdalek. Destas, $80 \%$ se localizam no lado esquerdo, $15 \%$ no lado direito e $5 \%$ são de ambos lados. É predominante em mulheres (MOREIRA, MEL, et al., 2004).

Cerca de $10 \%$ são diagnosticadas após o período neonatal, sendo a maioria descoberta acidentalmente em exames (NETTO JMS, et al., 2015; OLIVEIRA DRCF e JUNIOR AJR, 2008). No adulto, é rara, com incidência entre 1 e $5 \%$, representando $5 \%$ das Hérnias de Bochdalek. Cerca de $25 \%$ dos casos são assintomáticos. Em adultos e idosos, dados da literatura evidenciam uma clínica tardia representada por sintomas agudos cardiovasculares, respiratórios e quadros obstrutivos abdominais (MONTEIRO MCM, et al., 2017).

Sua apresentação ocorre habitualmente na infância, com maior incidência em neonatos. Em decorrência de possível hipoplasia pulmonar como condição associada (MOREIRA, MEL, et al., 2004), constitui causa de insuficiência respiratória aguda e de grande morbimortalidade.

O diagnóstico, apesar de ser possível a partir de aproximadamente 15 semanas de vida intra-útero por ultrassonografia (MOREIRA, MEL, et al., 2004), geralmente é feito nas primeiras oito semanas após o nascimento, correspondendo a 5 a $25 \%$ de todas as Hérnias de Bochdalek. Na criança e no adulto, exames complementares com radiografia de tórax de tomografia computadorizada auxiliam na definição da condição (BOCHDALEK VA, 2018).

Independentemente da idade em que for detectada, a hérnia diafragmática deve ser abordada cirurgicamente, na maioria das vezes por via abdominal, com realocação dos órgãos e correção da falha, fazendo uso de prótese caso necessário (MOREIRA, MEL, et al., 2004). Apesar de não haver consenso a respeito, pode-se também realizar abordagem por via torácica ou mista. Atualmente, é preferível o uso de técnicas minimamente invasivas como videolaparoscopia ou videotoracoscopia (BOCHDALEK VA, 2018). A Hérnia de Bochdalek é, portanto, diagnosticada principalmente pelas suas manifestações clínicas e por exames de imagem, sendo sua identificação em adultos um desafio pela inespecificidade dos sintomas. $O$ tratamento desta condição é cirúrgico, com redução das vísceras herniadas e rafia do defeito diafragmático (YAGMUR Y, et al., 2015). 
Desta maneira, o objetivo deste artigo é relatar um caso de hérnia de Bochdalek em adulto e discutir sua prevalência e manifestações clínicas.

\section{RELATO DE CASO}

Trata-se de um estudo descritivo do tipo Relato de Caso. Esse estudo foi executado por meio da realização de anamnese completa e de revisão do prontuário e de imagens de radiografia e tomografia computadorizada realizadas em um hospital na cidade de Franca, São Paulo.

Paciente do sexo masculino, 37 anos, deu entrada na emergência com queixa de dor abdominal difusa, continua, com 5 dias de evolução. Concomitante ao quadro álgico, apresentava náuseas, vômitos fecaloides, inapetência e parada de eliminação de flatos e fezes. O quadro era refratário ao uso de antieméticos e de antiácidos, mas com melhora parcial ao ficar em repouso e imóvel. Fez uso de cocaína em grande quantidade no dia de início do quadro, obtendo piora da dor. Em conjunto, apresentou dispneia, com piora ao decúbito e melhora ao sentar e em ortostatismo. Negou patologias de base, medicamentos contínuos, cirurgias prévias e traumas. Referiu história de pneumonia há 18 anos, tendo sido submetido a drenagem de tórax à esquerda e boa resolução do quadro. Negou tabagismo e referiu ser etilista há 8 meses e usuário de cocaína há 6 anos.

Ao exame físico, o abdome encontrava-se distendido, ruídos hidroaéreos presentes e aumentados, timpânico à percussão, pouco flácido e doloroso à palpação profunda difusamente. Não havia irritação peritoneal. O paciente apresentava-se taquipneico, com murmúrio vesicular fisiologicamente bem distribuído e sem ruídos adventícios.

De acordo com a anamnese e exame físico, foi feita a hipótese de abdome agudo obstrutivo. Foi solicitado exames laboratoriais e de imagem.

Os resultados: hemoglobina $16,3 \mathrm{~g} / \mathrm{dL}$, hematócrito $47,6 \%$, plaquetas 221.000 , glóbulos brancos 3.800 com $22 \%$ de bastões e segmentados $40,2 \%$, lactato $5,7 \mathrm{mg} / \mathrm{dL}$, PCR $135,8 \mathrm{mg} / \mathrm{dL}$ e gasometria arterial sem alterações. Apesar de conter exame laboratorial não infeccioso, demonstra traços de inflamação uma vez que a proteína $\mathrm{C}$ reativa, marcadora inespecífica de processo inflamatório, encontra-se aumentada.

$\mathrm{Na}$ tomografia de abdome com contraste foi visualizada importante distensão difusa de alças do intestino delgado e cólon, que se estendia até cólon transverso, ceco dilatado e com sinais sugestivos de pneumatose intestinal (Figuras 1 e 2).

Figura 1 - Distensão de alças na tomografia

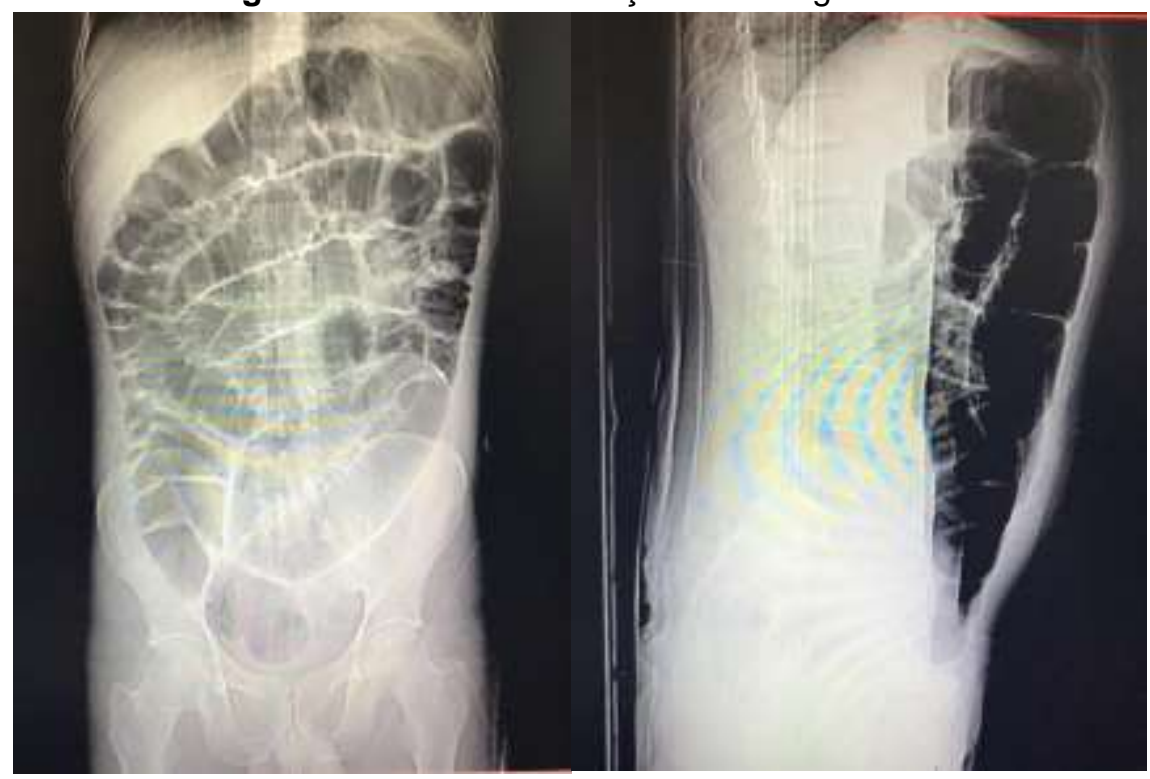

Fonte: Silva FRAD, et al., 2019. 
Figura 2 - Distensão de alças na tomografia.

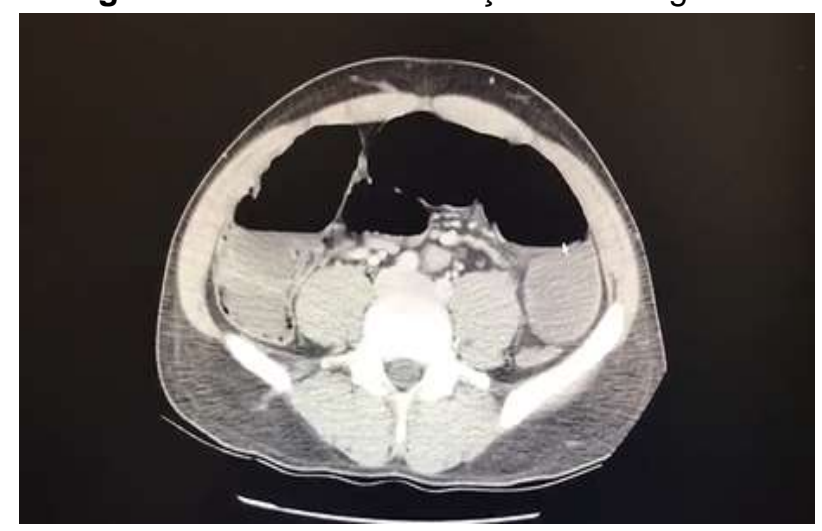

Fonte: Silva FRAD, et al., 2019.

Foi indicado laparotomia exploradora de urgência, com início imediato de antibioticoterapia. No intraoperatório, foi identificado distensão difusa de alças do intestino delgado a $40 \mathrm{~cm}$ do Treitz, distensão de cólon transverso e presença de hérnia diafragmática póstero-lateral esquerda com cólon transverso e omento encarcerados (Figura 3).

Figura 3 - Alças distendidas no intraoperatório.

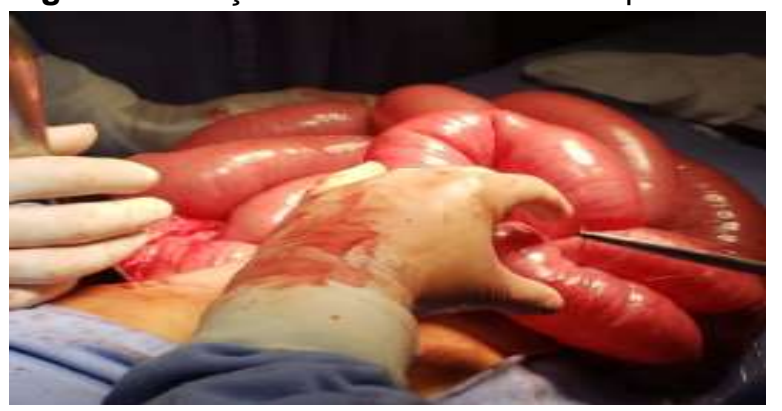

Fonte: Silva FRAD, et al., 2019.

Realizada a abertura do anel herniário de localização póstero-lateral esquerda, e manejo cuidadoso do conteúdo (cólon transverso e omento) para a cavidade abdominal. Foi evidenciado sinais macroscópicos de sofrimento vascular do cólon transverso, sem presença de necrose tecidual. (Figura 4).

Figura 4 - Redução de alça intestinal e omento.

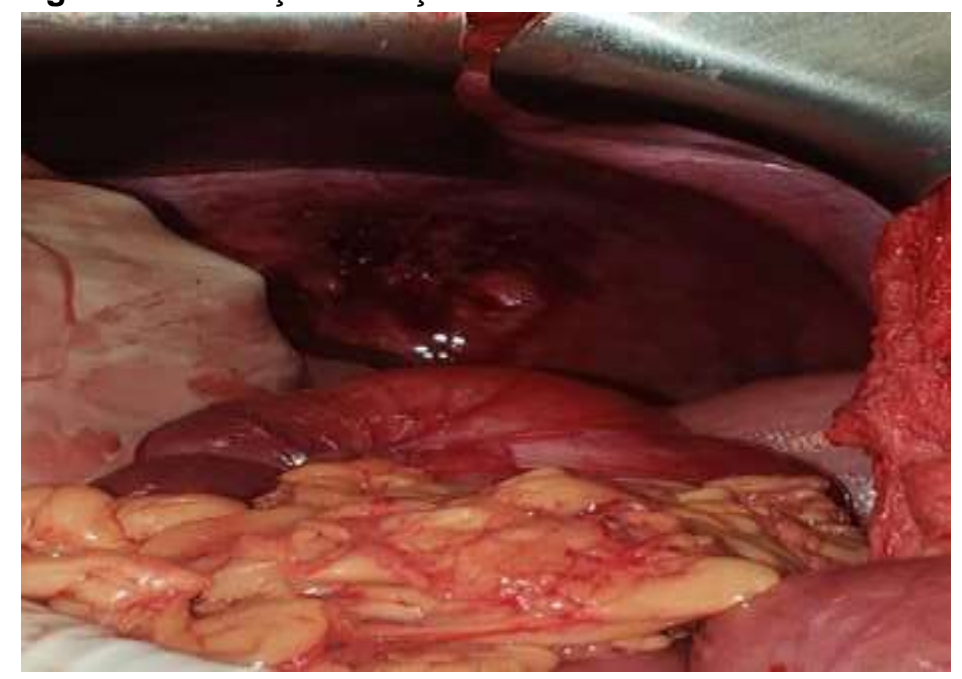

Fonte: Silva FRAD, et al., 2019. 
Feito rafia do defeito diafragmático, em ponto X separados de prolene (Figura 5). Liberado cólon esquerdo da goteira parietocólica e realizado colectomia segmentar de cólon transverso e descendente, com anastomose laterol-lateral grampeada a Barcelona. Procedimento sem intercorrências.

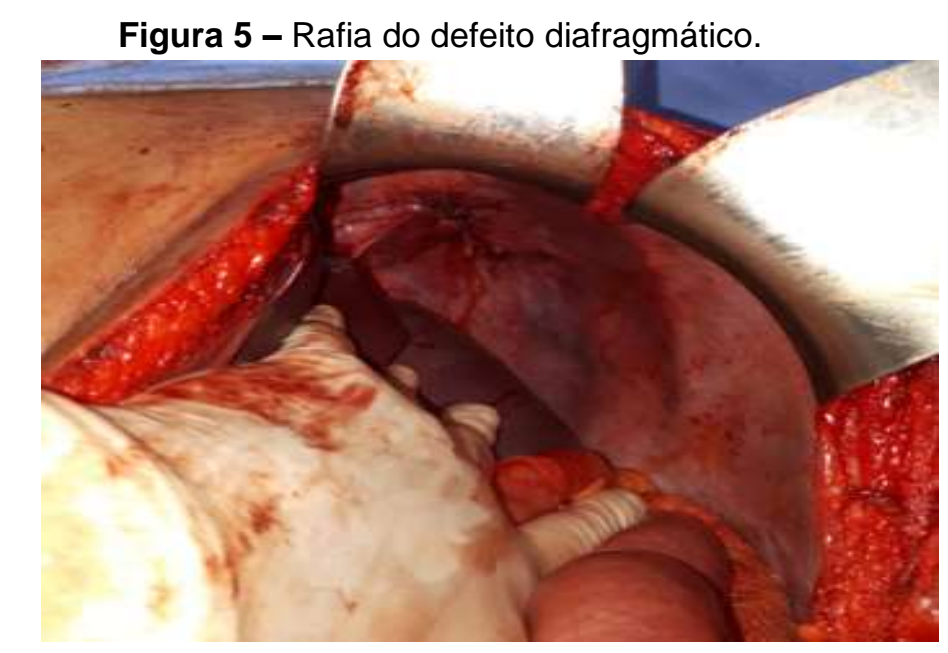

Fonte: Silva FRAD, et al., 2019.

No pós-operatório, foi realizada radiográfica de tórax de controle a qual evidenciou coleção de liquido em base de hemitórax esquerdo, compatível com derrame pleural e presença de pneumoperitônio residual (Figura 6). Após o procedimento cirúrgico, o paciente manteve-se estável e apresentou evolução clínica satisfatória, com alta hospitalar no $7^{\circ}$ dia após ato cirúrgico.

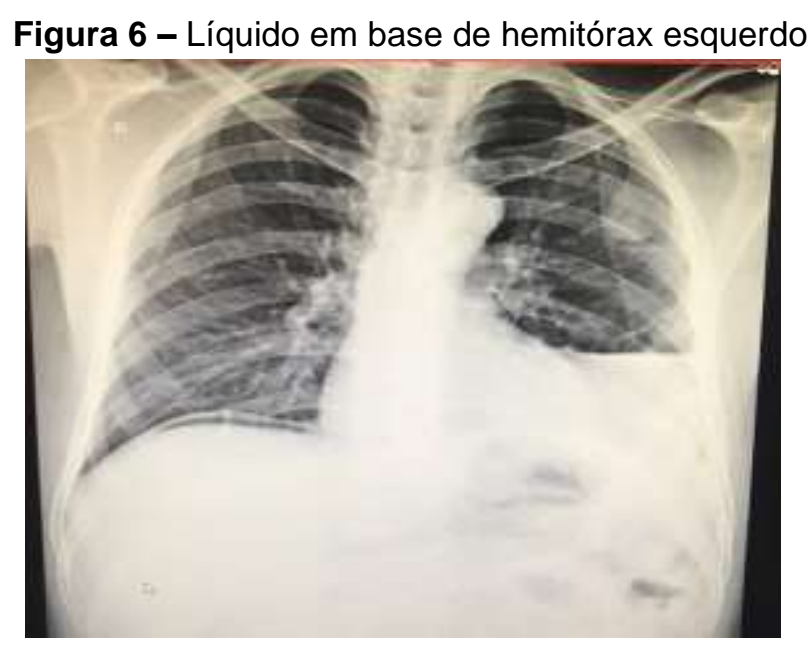

Fonte: Silva FRAD, et al., 2019.

\section{DISCUSSÃO}

A hérnia de Bochdalek é uma patologia rara em adultos e representa 0,17-6\% de todas as hérnias diafragmáticas (SUTEDJA B e MULIANI Y, 2015).

Sua localização é mais prevalente à esquerda pois a hemicúpula direita se desenvolve precocemente e o fígado previne a protrusão de vísceras abdominais. Porém, quando em adultos, as hérnias em hemicúpula direita são mais frequentes e acometem predominantemente mulheres (LAAKSONEN E, et al., 2009; ROBINSON PD e FITZGERALD DA, 2007). Assim, a literatura traz dados distintos da realidade aqui apresentada, uma vez que o paciente é masculino e portador de hérnia diafragmática congênita a esquerda. 
Na presença de Hérnia de Bochdalek sintomática em adultos, torna-se complexo realizar o diagnóstico da mesma pelo fato de $25 \%$ dos casos serem assintomáticos; deste modo, há subdiagnóstico. Calcula-se que a incidência de assintomáticos é de 1 entre 2.000 e 7.000 em estudos de autópsia (HAMID K, et al., 2012; ZHOU Y, et al., 2014). Além disso, quando sintomáticas, os sintomas são inespecíficos. O paciente em questão negou qualquer sintoma pregresso ao quadro, sendo diagnosticado pelo fato de apresentar a forma aguda mais preocupante da condição, representada pelo estrangulamento herniário.

Comumente, a Hérnia de Bochdalek manifesta-se no adulto por sintomas relacionados a complicações decorrentes de vísceras abdominais herniadas: encarceramento, estrangulamento ou perfuração da víscera com intercorrência séptica (SALAÇIN S, et al., 1994). Essa apresentação pode ser desencadeada por uma série de fatores, como trauma, tosse excessiva, gestação e trabalho de parto (LAAKSONEN E, et al., 2009; ROBINSON PD e FITZGERALD DA, 2007), os quais não foram identificados na anamnese do paciente analisado.

Quando o quadro agudo ocorre, pode apresentar manifestações gastrintestinais como náusea, vômitos, dor e distensão abdominal, dor lombar e também manifestações de natureza respiratória, como dispneia e dor torácica (LOSANOFF JE e SAUTER ER, 2004). O efeito de massa no tórax pode ocasionar alterações no sistema cardiorrespiratório, decorrentes da compressão das estruturas existentes. Tais sintomas são semelhantes aos apresentados pelo paciente do caso, sendo que o mesmo exibia, em associação, inapetência e parada de eliminação de flatos e fezes, típicos de quadro de abdome obstrutivo.

O paciente relatado apresentou piora do quadro álgico após uso de grande quantidade de cocaína. O uso desta substância de forma abusiva e aguda pode provocar vasocontrição generalizada e levar a um processo isquêmico dos tecidos pois a mesma altera a recaptação de neurotransmissores (como noradrenalina e dopamina), aumentando sua concentração em níveis sanguíneos. Isto pode provocar uma série de alterações gastrointestinais, musculoesqueléticas, cardíacas e pulmonares, podendo justificar o agravamento do quadro representado (BURKE KA E, et al., 2014).

O diagnóstico das hérnias diafragmáticas não traumáticas em adultos se assenta, sobretudo, na tradução radiológica da existência de vísceras ocas acima do diafragma. A dificuldade em realizar o diagnóstico radiológico pode ocorrer em casos nos quais não é visualizado gás próximo ao diafragma, ou na presença de massas ou derrame pleural, comprometendo a investigação (MOTA JC, et al., 1996). No entanto, a radiografia de tórax não foi realizada e a tomografia de abdome não era clara para fins diagnósticos. Deste modo, o diagnóstico foi feito no intraoperatório, identificando hérnia diafragmática póstero-lateral esquerda com cólon transverso e omento encarcerados.

O tratamento de escolha engloba a redução do conteúdo herniário para a cavidade peritoneal de forma cuidadosa e reparo do defeito diafragmático. Dados da literatura priorizam a intervenção cirúrgica aberta, principalmente em quadros urgentes, de preferência por via abdominal ou torácica, se casos mais complicados (LAAKSONEN E, et al., 2009).

Atualmente, a via laparoscópica é considerada uma técnica pouco invasiva, com baixas taxas de complicação, que pode ser uma opção em situações eletivas (YAGMUR Y, et al., 2015). No caso deste paciente, foi realizada laparotomia e o paciente se apresentou estável. Apesar da evolução com derrame pleural à esquerda, uma complicação do pós-operatório imediato, foi resolutivo por medidas somente conservadoras mantendo satisfatório o progresso terapêutico.

\section{CONSIDERAÇÕES FINAIS}

A hérnia de Bochdalek comumente manifesta-se no período neonatal. Em adultos, sua ocorrência é rara, predominando ao lado direito e em mulheres. Pode se apresentar com sintomas gastrintestinais e respiratórios inespecíficos e quadro agudo de estrangulamento, encarceramento ou perfuração. Há, portanto, a necessidade de raciocínio clínico para seu diagnóstico associado a técnicas de imagem. A cirurgia visa identificar o conteúdo herniário, realizar sua redução e corrigir o defeito diafragmático. 


\section{REFERÊNCIAS}

1. TAVARES FLS, et al. Hérnia diafragmática congênita em adulto. Relatos Casos Cir. 2016; 4: 1-3.

2. BROWN GL, RICHARDSON JD. Traumatic diaphragmatic hernia: a continuing challenge. Ann Thorac Surg. 1985; 39: 170-173.

3. MOREIRA, MEL, et al. O recém-nascido de alto risco: teoria e prática do cuidar [online]. Rio de Janeiro: Editora FIOCRUZ, 2004; 564 p.

4. NETTO JMS, et al. Hérnia de Bochdalek à direita em adulto, associada à síndrome colestática: Relato de Caso. ABCD Arq Bras Cir Dig. 2015; 28(4): 293-301.

5. OLIVEIRA DRCF, JUNIOR AJR. Hérnia de bochdalek em adulto. Rev Col Bras Cir. 2008; 35(1).

6. MONTEIRO MCM, et al. Hérnia de Bochdalek em adulto: Relato de caso. Revista de Saúde. 2017; 08(1).

7. BOCHDALEK VA. Obstrução Gástrica em Adulto por Hérnia Diafragmática Congênita. Rev Med Minas Gerais. 2018; 28: e-2003.

8. YAGMUR Y, et al. Bochdalekhernia: a rare case reportofadult age. Ann Med Surg (London). 2015; 5: 72-5.

9. SUTEDJA B, MULIANI Y. Laparoscopic repair of Bochdalek hernia in an adult woman. Asian J Endosc Surg. 2015; 8(3): 354-356.

10. LAAKSONEN E, et al. Right-sided Bochdalek hernia in an adult: a case report. J Med Case Reports. 2009 ; 3.

11. ROBINSON PD, FITZGERALD DA. Congenital diaphragmatic hernia. Paediatr Respir Rev. 2007; 8: $323-335$.

12. HAMID K, et al. Symptomatic Bochdalek hernia in an adult. JSLS. 2012; 14: 279-281.

13. ZHOU Y, et al. Giant congenital diaphragmatic hernia in an adult. J Cardiothorac Surg. 2014; 9: 31.

14. SALAÇIN S, et al. Bochdalek hernia in adulthood: a review andautopsy case report. J Forensic Sci. 1994; 39(4): $1112-1116$.

15. LOSANOFF JE, SAUTER ER. Congenital posterolateral diaphragmatic hernia in an adult. Hernia. $2004 ; 8: 83$.

16. Burke KA, et al. Diagnosing abdominal tuberculosis in the acute abdomen. Int J Surg. 2014; 12(5):494-9.

17. MOTA JC, et al. Hernia de Bochdalek no Adulto: Diagnostico Facil? Rev Port Pneumol II. 1996; 2: 141-143. 